\title{
TRANSFORMACIONES TERRITORIALES EN EL NORTE DE MARRUECOS ${ }^{1}$.
}

\section{LAND CHANGE IN NORTHERN MOROCCO.}

\author{
Jesús Gabriel Moreno Navarro² \\ Universidad de Sevilla \\ jgamore@us.es
}

Recibido: febrero, 2012.

Versión final aceptada: noviembre, 2012.

PALABRAS CLAVE: desarrollo local, cambio territorial, cartografía, cooperación internacional.

KEY WORDS: local development, land change, cartography, international cooperation.

\section{RESUMEN}

Los miembros del equipo de cooperación internacional "Territorio Andaluz, Desarrollo e Innovación" se han implicado durante más de una década en proyectos de desarrollo sobre zonas colindantes con el Estrecho de Gibraltar. En este artículo se resume el perfil y las conclusiones obtenidas en los proyectos de cooperación desarrollados por el grupo, así como otros hechos relacionados con las transformaciones territoriales del Norte de Marruecos. En la actualidad, las acciones se basan en la construcción de grandes puertos y carreteras cercanas a los nuevos centros turísticos de la costa. Los impactos son evidentes en el medio ambiente y en el contexto social. La transformación radical ha aumentado el atractivo en las zonas urbanas, incrementando el éxodo rural que ya era de por sí considerable. Por otra, la pérdida de calidad de vida la asociamos a la merma de suelo cultivable y el deterioro del medio al poner en cultivo tierras forestales. La agricultura es de subsistencia y como tal está sometida a la supervivencia de las familias en un medio cada vez más desfavorable. Las intervenciones en este medio podrían tomar como ejemplo los patrones que se han aplicado en el entorno rural español en el pasado, cuyo deterioro siguió pautas similares en un período de tiempo más largo.

\footnotetext{
1 El presente artículo procede de la comunicación científica presentada en las Jornadas de Estudios Regionales: Redes y sus territorios: Incidencia en el desarrollo regional. AGE. Sevilla, Junio de 2012.

2 Además de J.G Moreno Navarro, han participado en la elaboración de este trabajo por orden alfabético, Francisco Manuel Campaña Villegas, Luís Domínguez Villoría, Rafael Fernández Silva, Marta López Heredia, José Manuel Moreno Martínez y Manuel Ramón Ternero Vega.
}

ISSN: 0212-8594 ISSN-e: 2340-2776 № DOI: http://dx.doi.org/10.12795/rea.2011.i28.01 


\begin{abstract}
Team members of international cooperation "Territory Andaluz, Development and Innovation" has been involved for over a decade in development projects on areas adjacent to the Strait of Gibraltar. This article summarizes the profile and the conclusions of cooperation projects developed by the group, as well as other facts related to territorial changes in northern Morocco. Currently, the actions are based on the construction of large ports and roads near the new resorts on the coast. The impacts are evident in the environment and in the social context. The radical transformation has increased the attractiveness in urban areas, increasing rural exodus and was itself significant. Furthermore, loss of quality of life associate with the decline of arable land and the deterioration of the forest land put into cultivation. Agriculture is subsistence and as such is subject to the survival of families in an environment increasingly unfavorable. Interventions in this medium could take as an example the patterns that have been implemented in rural Spanish in the past, whose deterioration followed a similar pattern on a longer time period.
\end{abstract}

ISSN: 0212-8594 ISSN-e: 2340-2776 № DOI: http://dx.doi.org/10.12795/rea.2011.i28.01 REA 28 (2011):1-15

http://www.publius.us.es/estudios_andaluces 


\section{INTRODUCCIÓN.}

El grupo de cooperación vinculado a la Asociación Territorio Andaluz. Desarrollo e Innovación es de reciente creación, pero la mayoría de sus miembros sostienen una trayectoria de más de una década trabajando en la zona en proyectos de cooperación (AECID, Consejería de la Presidencia de la Junta de Andalucía) e I+D+I (Plan Nacional). En la presente comunicación se resumen los hitos más importantes de dicha trayectoria y la naturaleza de los proyectos emprendidos. Todos los proyectos tienen en común la consideración del entorno del Estrecho de Gibraltar como un centro de vital interés geográfico. Se presenta como la frontera más desigual del mundo y que a su vez está siendo receptora de una transformación radical del entorno con políticas desarrollistas a ambos lados del Estrecho. En este caso nos referimos tan sólo a los proyectos que han tenido como objeto el estudio de las transformaciones en el norte de Marruecos, concretamente aquellos que han producido documentación cartográfica relevante, como son los financiados por la Agencia Española de Cooperación Internacional y la Oficina de Cooperación de la Universidad de Sevilla.

La mencionar el norte de Marruecos pretendemos situarnos en la parte africana del Entorno del Estrecho de Gibraltar. Aunque existe una Región Norte propiamente dicha en una subdivisión sin consideración administrativa y que abarcaría desde Larache hasta Oujda en la frontera con Argelia, las divisiones administrativas que contienen a las zonas de estudio se ajustan a la región Tánger-Tetuán. Como tal se pueden encontrar datos estadísticos desagrupados sobre este nivel territorial.

La región Tanger-Tetuán está formada por las cuatro provincias Tánger, Tetuán Chaouen y Larache, una región que en los comienzos de nuestros trabajos abarcaba una extensión de $11.570 \mathrm{Km} 2$. Las estadísticas con la que contábamos en estos momentos (2002) con datos del censo de 1994 daban una población de poco más de dos millones de habitantes, siendo entonces la proyección demográfica para el año 2002 de $2.430 .000 \mathrm{~h}$. El últmo censo de 2004 daba una población de 2.460.220 (Direction General de la Statistique, 2011). Los datos de desempleo variaban del $12 \%$ al 19\% según las fuentes (Chikhaoui, 2000; Direction General de la Statistique, 2000).

Las cuatro provincias están marcadas físicamente por su orografía rifeña, las influencias climatológicas del Estrecho de Gibraltar y una población que sufre las consecuencias de éxodo rural provocado por la economía de subsistencia que aún permanece en sus valles. Sin embargo, cada provincia tiene unos rasgos que la diferencian de las demás; así en Chaouen, el paisaje serrano alberga una mayor connotación rural que va siendo absorbida más lentamente por el rápido crecimiento urbano del núcleo cabecera. Su economía de origen rural, ha encontrado en el turismo y el comercio de artesanía a los dos motores de su progreso. Larache mantiene la esperanza en la riqueza de su sector primario; la actividad pesquera y una desarrollada industria de transformación de productos agrícolas destacan con evidencia en un

ISSN: 0212-8594 ISSN-e: 2340-2776 № DOI: http://dx.doi.org/10.12795/rea.2011.i28.01

REA 28 (2011):1-15

http://www.publius.us.es/estudios_andaluces 
entorno de desolación empresarial y deterioro urbanístico. La provincia de Tánger se vuelca hacia la ciudad costera, que a su vez organiza su economía en torno al puerto y a la zona franca. En su desarrollo urbanístico se deja ver su reciente pasado internacional y cosmopolita, habiendo favorecido cierto nivel en el sector turístico.

El comercio tanto de Tánger como de Tetuán están muy marcados por el de tipo franco y el inevitable contrabando que algunos consideran imprescindible para el abastecimiento de la población. De cualquier forma, esta circunstancia añade un carácter informal a la economía de la zona que dificulta la elaboración de un diagnóstico territorial en la Región. Tetuán, ha recibido en los últimos años una gran masa poblacional proveniente de las comunas rurales, aumentando de forma considerable la proporción de población desempleada Uno de los alicientes que ha acelerado dicho éxito es la ventaja que supone el privilegio del visado para pasar la frontera de Ceuta, por el mero hecho de estar empadronado en Tetuán. Un entorno de degradación ambiental con una gran proporción de población en edad laboral que se desplaza fácilmente por un territorio con escasas oportunidades y que comprensiblemente se ve atraída por la aventura de cruzar las ocho millas que les separan del sueño europeo. Ocho millas que tiene la frontera política y socioeconómica más desequilibrada del mundo. $Y$ la tendencia es a que ese desequilibrio se acreciente.

Figura 1. Comparativa de la evolución del IDH entre Marruecos y España.

\begin{tabular}{|l|l|l|l|l|l|l|}
\hline & \multicolumn{4}{l|}{ Puesto en el IDH } & \multicolumn{4}{l|}{ Renta per capita } \\
\hline & 2002 & 2004 & 2011 & 2002 & 2004 & 2011 \\
\hline Marruecos & 123 & 125 & 130 & 19.472 & 21.460 & 25.508 \\
\hline España & 21 & 20 & 23 & 3.546 & 3.810 & 4.196 \\
\hline
\end{tabular}

Fuente: Moreno Navarro, J.G. (2006) e IDH 2011.

\section{PROYECTOS DE INVESTIGACIÓN DIRIGIDOS POR MIEMBROS DE LA FUNDACIÓN EN RELACIÓN CON LAS TRANSFORMACIONES TERRITORIALES.}

En este artículo convergen la experiencia de varios proyectos dirigidos o codirigidos por los solicitantes: a) los anteriores PCl 2007 y PCl-2008 "Estrategias de Desarrollo Sostenible a partir de un SIG de usos del suelo y riesgos de erosión", b) "la evaluación del SDAU del Estrecho (TMSA 2004)" y c) el proyecto I+D del Plan Nacional (TRA2008) "Bases para la inserción del Estrecho de Gibraltar en los corredores de transporte intermodal a través de la modelización con SIG". Los intereses de investigación de los componentes del equipo se concentran en el entorno del SDAU (Écheme Directeur D’amenagement Du Detroit) donde se está llevando a cabo una reordenación radical del territorio, usos del suelo, infraestructuras, etc. desde el año 2004. 
Si bien el equipo se constituyó para la realización del proyecto PCl 2007 sobre la Cuenca del Oued Laou, la zona afectada por el SDAU acaparó nuestra atención por constituir un laboratorio geológico y geográfico ideal sobre el que la mirada de la sostenibilidad debía fijarse. Además la cartografía de la zona queda cubierta en su totalidad por las escenas LANDSAT que ya habíamos corregido geométricamente y clasificado durante los PCl 2007-08 sobre Oued Laou. Esto quiere decir que la parte más laboriosa del trabajo cartográfico y desarrollo de metodología ya la había hecho el equipo. En este caso, se trata también de un entorno de base rural y forestal montañoso, pero que ha sido convertido en un área estratégica para los intereses desarrollistas del Reino de Marruecos.

Para dar respuesta a una situación socioeconómica desfavorecida en las provincias de Tánger y Tetuán, entre otras razones justificadas, se ha construido un macro-puerto, una zona de actividades logísticas, zona franca, etc. de dimensiones espectaculares. En la última década las capitales de ambas provincias han recibido el éxodo masivo de una población rural que abandona la agricultura y ganadería de subsistencia aumentando las tasas de desempleo en estas dos ciudades, cuya situación pretende aliviar la nueva ordenación estratégica de la zona. Si en el Valle del Oued Laou presenciamos como los cambios de actividades están propiciando la pérdida de suelo agrícola, en el caso de las recién creadas Provincia de Mdiq-Fnideq y Prefectura de Fahs-Anjra, observamos hoy como la nueva ordenación del litoral con una profunda área de influencia en el interior, presiona física y funcionalmente sobre un débil entorno rural y forestal en evidente regresión.

La inestabilidad del terreno agredido ha provocado desprendimientos y coladas que han destruido hábitat, tramos de autopistas y otras infraestructuras. Nos encontramos por lo tanto con un entorno rural depredado, un contexto urbano que aumenta su tasa de desempleo con el éxodo rural y una política desarrollista para absorber la demanda de empleo a costa de la degradación del medio rural. Frente a este círculo insostenible se planteó dotar al ámbito académico investigador con sistemas de información que asesorarían las acciones desde una perspectiva de sostenibilidad. Los productos de las tecnologías de la información geográfica son muy gráficos en la demostración causaefecto.

De este modo se ha aportado una base documental para favorecer el asesoramiento a los implicados en esta vorágine de transformación territorial. Se reunieron en esta propuesta objetivos como, A) Transmisión y difusión de conocimientos y tecnologías (Teledetección y SIG) para abordar problemas de desarrollo humano, B) Promover la conservación y uso sostenible del recurso suelo C) Asesoramiento en la ordenación del territorio desde una perspectiva sostenible y D) Desarrollo Rural, siguiendo los objetivos prioritarios de la Cooperación Española. Las bases iniciales de este proyecto fueron establecidas por el equipo en el encuentro que tuvo lugar en la sede de la Autoridad Portuaria de Tanger-Med y la Universidad Abdelmalek Essaadi en marzo del 2009 financiado por una Beca Bancaja.

ISSN: 0212-8594 ISSN-e: 2340-2776 № DOI: http://dx.doi.org/10.12795/rea.2011.i28.01

REA 28 (2011):1-15

http://www.publius.us.es/estudios_andaluces 


\section{OBJETIVOS DE LOS PROYECTOS PCI.}

La falta de información cartográfica en Marruecos se hace evidente cada vez que se pretende trabajar sobre contenidos territoriales. En este caso partimos de unas fuentes primarias para elaborar una cartografía fundamental, que si bien tiene un objetivo temático concreto como son los usos del suelo y riesgos erosivos y climatológicos varios, la naturaleza de su elaboración sobre ortoimágenes ha sido de gran utilidad en otros ámbitos de estudio. Si bien el primer proyecto $\mathrm{PCl}$ 2007-2008 de este equipo se enfocaba a la elaboración de estrategias y planteaba llegar hasta los habitantes del lugar con un enfoque didáctico, en el proyecto 2009-2010 el enfoque fundamental han sido los profesionales, cooperantes e investigadores del medioambiente y de manera indirecta a los poderes fácticos de la Región. En este caso la zona es más accesible que la del Valle del Oued Laou, por lo que facilitó el desplazamiento del equipo español y mejoró el tiempo neto de trabajo sobre el total empleado. También es de agradecer el menor riesgo que supone el acceso a la zona del SDAU del Estrecho, frente a los riesgos físicos que suponían los accesos al Valle del Oued Laou. Accesorio a la composición del equipo, hay que incluir la participación activa de trabajos Fin de Carrera y Tésis de Master y Doctorado con Mención de Calidad cuya participación fue costeada a cargo de presupuestos externos a la AECID.

Se planteó obtener una herramienta que permita evaluar los cambios que se están produciendo en un ámbito territorial cuyos usos están evolucionando dramáticamente. La elaboración de la herramienta conlleva el uso de una metodología experimentada y el dominio de unas técnicas avanzadas como son las tecnologías de la información geográfica. La consolidación de este bagaje constituye un objetivo de por sí. La experiencia del equipo con las imágenes LANDSAT, QUICKBIRD, ALOS-PRISM, SPOT, etc, ha demostrado la viabilidad de la metodología empleada. Actualmente el equipo cuenta con una base de datos de imágenes satélites y cartografía temática de elaboración propia de considerable volumen y calidad que continua enriqueciéndose.

Ello supone la formación técnica de sus componentes, capacidad de aprovechar los medios técnicos disponibles y una buena disposición al trabajo en equipo. Este aspecto suponía un objetivo transversal en el anterior $\mathrm{PCl} 2008$ y su consolidación es ahora un propósito continuo. El objetivo general ha sido ayudar a poner de manifiesto la rápida degradación del medio rural y explicar su evolución en la región Tánger-Tetuán, tomando como ejemplo una zona de rápida urbanización. De este modo complementamos el modelo rural tradicional de Oued Laou (PC12007-2008) con debilidades básicamente internas (explotación de recursos insostenible) con el del SDAU del Estrecho que supone una amenaza externa (presión sobre la ocupación del suelo).

ISSN: 0212-8594 ISSN-e: 2340-2776 № DOI: http://dx.doi.org/10.12795/rea.2011.i28.01

REA 28 (2011):1-15

http://www.publius.us.es/estudios_andaluces 
Para ello perseguimos el objetivo específico de elaborar una cartografía temática objetiva basada en imágenes satelitales con bandas en el espectro visible, infrarrojo y banda pancromática, que son testigo y prueba indiscutibles de la realidad. El objetivo específico final es la edición de esta cartografía en los formatos más asequibles, para lo que se utilizó el acceso FTP a la base de datos en el servidor de la Facultad de Geografía e Historia, como se ha hecho hasta el momento a falta de un servidor apropiado en la Facultad de Ciencias de Tetuán. La participación de integrantes del equipo de otras universidades (UAB), así como de personal externo y otros gastos no cubiertos por las ayudas $\mathrm{PCl}$ se financiaron con otras ayudas como las del Plan Propio de la Universidad de Sevilla.

\section{METODOLOGÍA Y TÉCNICAS.}

En los proyectos PCI hubo dos fases a completar: la elaboración del SIG y en segundo lugar su operación y difusión. La elaboración del SIG incluye levantamiento de la información, con trabajo de campo y tareas de laboratorio. Ya se llevó a cabo en gran parte por el equipo en el PCl 2008 sobre Oued Laou, pues las imágenes LANDSAT 5 y 7 corregidas (la mayor parte del trabajo de elaboración cartográfica) cubren una escena completa, donde la Cuenca del Oued Lau se encuentra en el extremo sur-este, mientras que la zona del SDAU queda muy cercana al centro nadir de la escena. De este modo, el equipo ya ha definido y experimentado el formato común de trabajo, las fuentes de información y la metodología de trabajo.

A la cartografía de planeamiento disponible (TMSA) confrontamos la cartografía temática sobre la evolución de usos y riesgos. Esta cartografía la elaboramos a partir de la clasificación de las imágenes LANDSAT en series temporales que evidenciaron la evolución de usos en relación con las acciones transformadoras emprendidas. Las imágenes LANDSAT 7 han resultado defectuosas por problemas en las lentes del satélite desde el año 2007, por lo que posteriormente a esa fecha se ha utilizado LANDSAT 5. El sensor TM de este satélite tiene una menor resolución espacial que su sucesor LANDSAT 7, algo que solucionamos satisfactoriamente con la adquisición de imágenes de los satélites ALOS-PRISM y QUICKBIRD cuyo coste fue asumido por el proyecto, como así sucedió en la experiencia anterior. En este caso la importancia de las infraestructuras, requirió la resolución espacial de estos satélites. No descartamos la inclusión de otras plataformas, pero es más conveniente aprovechar el camino andado. Se priorizó el suministro de imágenes sin coste, facilitando así la autosuficiencia en el acceso a las fuentes, tanto por evitar costes como por las dificultades legales y técnicas para adquirirlas por Internet en Marruecos.

En la segunda fase se configuró el SIG como herramienta dinámica de trabajo y su puesta en servicio a disposición del usuario final, algo que también se había avanzado en el PCI 2008. En este caso se contemplan dos niveles: A) con software SIG avanzado y herramientas de gestión y B) visualizadores SIG de libre distribución con cartografía SHAPE y GEOTIFF en CD. El primer nivel está dirigido a los usuarios avanzados del

ISSN: 0212-8594 ISSN-e: 2340-2776 № DOI: http://dx.doi.org/10.12795/rea.2011.i28.01

REA 28 (2011):1-15

http://www.publius.us.es/estudios_andaluces 
ámbito académico y el segundo tiene una intención más divulgativa, si bien la información contenida tendrá toda la calidad necesaria para su manipulación y edición, siguiendo los ejemplos del Instituto Cartográfico de Andalucía y otras instituciones. Esta segunda opción es muy útil como herramienta de trabajo en ONGs y labores educativas. El contenido del CD estará también disponible vía FTP. Software empleado: ArcGis 9.3, IDRISI KILIMANJARO, ENVI, (licencias de la Universidad de Sevilla) AMATEL, ArcExplorer (libre) y MIRAMON (Universidad Autónoma de Barcelona).

\section{EVOLUCIÓN TERRITORIAL.}

Partimos de una situación de excesiva polarización de la actividad económica en el Reino de Marruecos. La mayor parte de la producción industrial y el valor añadido de la economía marroquí se centra en el triángulo Rabat-Kenitra-Casablanca. Como puede verse en la figura siguiente, más de un $62 \%$ del valor de la producción industrial se concentraba a tres horas de desplazamiento de Casablanca.

Figura 2. Localización industrial. Isocronas desde Casablanca.

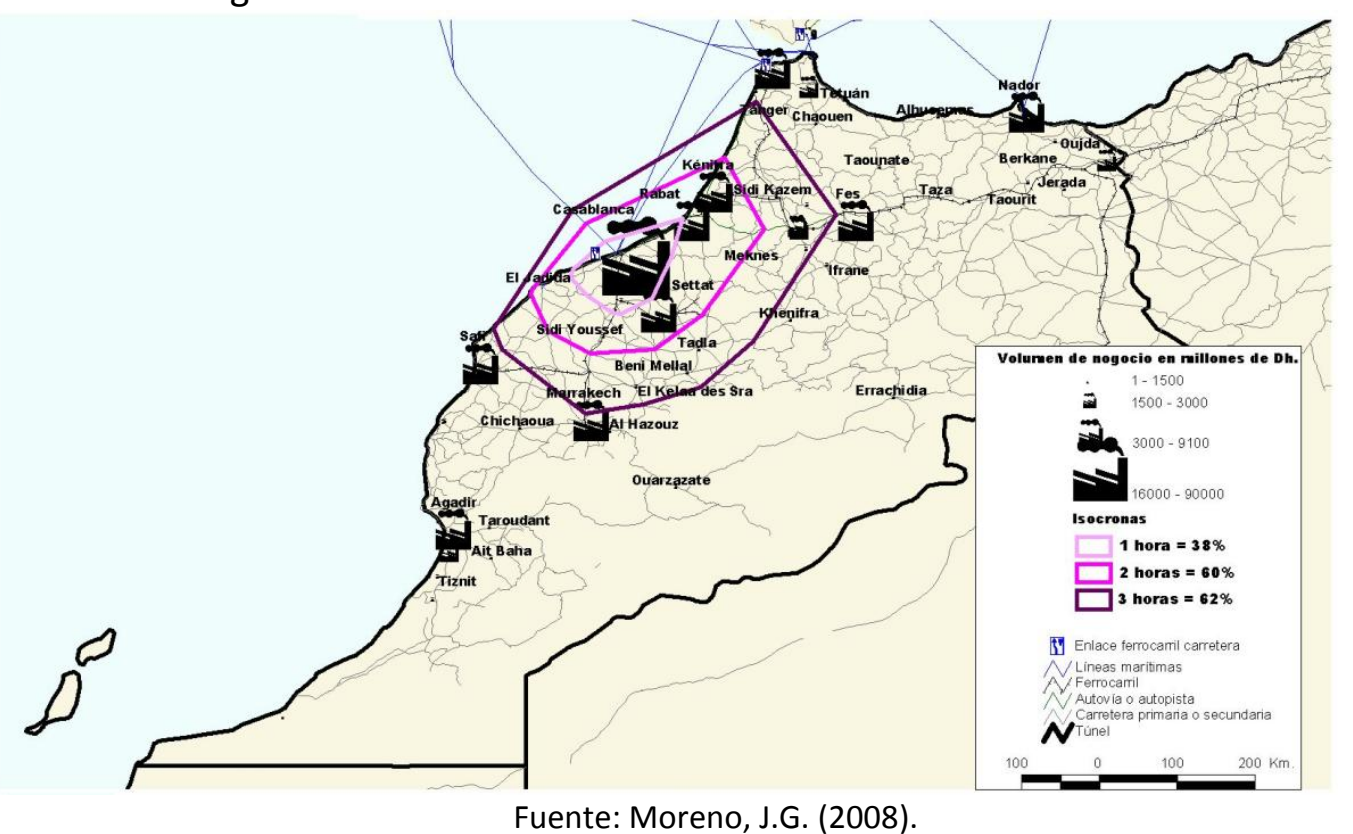

Esta excesiva polarización es sentida por la población, especialmente del norte de Marruecos con una herencia rifeña que la estigmatizó a los ojos del reinado de Hassan II. Bajo el reinado del heredero y actual monarca Mohammed VI cambió radicalmente esta postura y en la última década la inversión estatal desarrollista se ha volcado en la región Tánger-Tetuán, más concretamente en el macro proyecto Tánger-Med y la inversión inmobiliaria con vocación turística en la cornisa que va desde Ceuta a Martil junto a Tetuán.

ISSN: 0212-8594 ISSN-e: 2340-2776 № DOI: http://dx.doi.org/10.12795/rea.2011.i28.01

REA 28 (2011):1-15

http://www.publius.us.es/estudios_andaluces 


\subsection{EL SCHÉMA DIRECTEUR D'AMÉNAGEMENT DU DETROIT. SDAU. (ESQUEMA DIRECTOR DE ORDENACIÓN DEL ESTRECHO).}

Es el primer plan integral de ordenación estructural sobre el Norte de Marruecos del que hemos tenido información pública. Todo el proyecto gira en torno a la construcción de un macro-puerto $h u b^{3}$ aprovechando la tendencia creciente del transporte de contenedores y la situación ventajosa del Estrecho frente a este tipo de tráfico. La construcción del Puerto Tánger-Mediterráneo ha estado acompañada de la transformación de las zonas adyacentes para crear un entorno empresarial y urbanístico que ha permitido el desarrollo en cadena de actividades complementarias. Tal y como se previó en un principio, la puesta en funcionamiento del PTM ha resultado estructurante en la configuración de los transportes en el Reino de Marruecos, y por ende en el contexto competitivo del Estrecho de Gibraltar.

Figura 3. Cartografía resumida del SDAU.

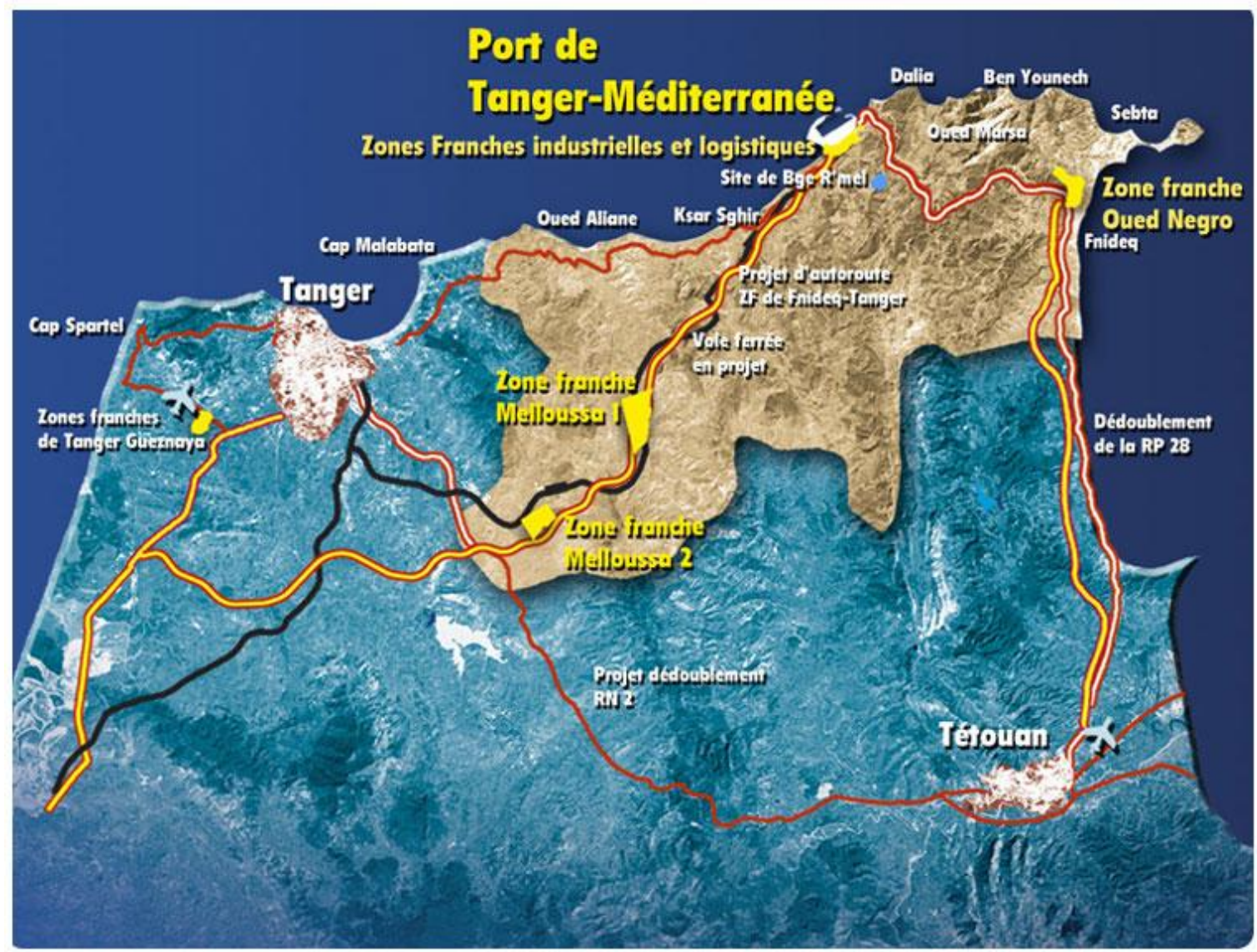

Fuente: TMSA, 2004.

\footnotetext{
${ }^{3}$ Tipo de puerto dedicado al tráfico de contenedores que no penetran en el Hinterland, sino que son almacenados y gestionados para redistribuirlos hacia otros destinos.
}

ISSN: 0212-8594 ISSN-e: 2340-2776 № DOI: http://dx.doi.org/10.12795/rea.2011.i28.01 REA 28 (2011):1-15

http://www.publius.us.es/estudios_andaluces 
La orientación tradicional del comercio exterior marroquí a partir de los polos económicos de Casablanca, Rabat y Kenitra va a tener su contrapeso gracias a esta apuesta por el Marruecos mediterráneo, lo que necesariamente habrá de dar mayor cohesión a la ordenación del Reino Alauita. La apuesta por bascular las estrategias de desarrollo hacia el Norte Mediterráneo marroquí puede llegar a animar la continuidad funcional del Arco Mediterráneo europeo, hoy en día diluido incluso antes de llegar a la provincia de Cádiz en España. Se están cumpliendo las perspectivas de crecimiento del mercado de los contenedores, así como la transformación del perfil de la mercancía importada y exportada desde Marruecos, justificando el respaldo a esta obra del Puerto Tánger-Mediterráneo.

Una vez en funcionamiento el PTM, el ámbito del Estrecho de Gibraltar se ha convertido en un auténtico centro direccional para el Norte de África y Sur de Europa, siguiendo el modelo de las concentraciones de superpuertos en el Mar del Norte. No obstante, para tener éxito no basta con la ventaja geoestratégica que presenta el Estrecho, sino que hay que materializar los ambiciosos proyectos de infraestructura y ordenación territorial siguiendo una tendencia estructurante.

EI PTM debe insertarse, pues, en un tejido suficientemente elaborado como para competir con espacios de alto nivel. Esto es lo que debe esperarse de un entorno con el alto nivel dotacional que corresponde a las zonas francas y a las actividades logísticas ya en servicio para este puerto hub. En cualquier caso la ubicación del nuevo puerto de Tánger presenta una clara vocación para captar el tráfico entre el Océano Atlántico y el Mar Mediterráneo, compitiendo con los puertos de Ceuta, Gibraltar y, sobre todo, Algeciras. Esta actuación habría que ponerla en relación con la otra política similar llevada a cabo en los 60 por parte del gobierno español con el Plan de Desarrollo Económico y Social del Campo de Gibraltar (MORENO, JG. 2007). Todo ello se vincularía a la especial atención que el nuevo monarca alauita está prestando a la región Norte. En otro orden debemos situar los proyectos concretos de infraestructuras.

Figura 4. Infraestructuras en proyecto y en ejecución en el Norte de Marruecos.

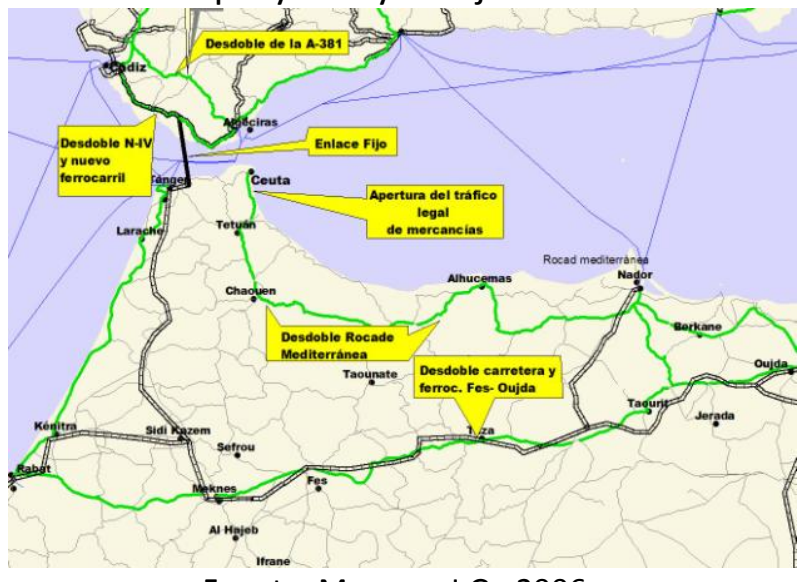

Fuente: Moreno, J.G., 2006.

ISSN: 0212-8594 ISSN-e: 2340-2776 № DOI: http://dx.doi.org/10.12795/rea.2011.i28.01

REA 28 (2011):1-15

http://www.publius.us.es/estudios_andaluces 


\subsection{EVOLUCIÓN EN LOS LÍMITES ADMINISTRATIVOS.}

La importancia del SDAU ha llegado a cambiar los límites administrativos de las provincias, creándose nuevas unidades para favorecer la gestión del territorio receptor de los planes de ordenación. La región Tánger-Tetuán estaba compuesta por las provincias de Tetuán, Tánger, Larache y Chaouen, coincidiendo casi en su totalidad con el antiguo Protectorado Español.

Actualmente, las provincias de Tánger y Tetuán han cedido territorio a una nueva provincia, Fahs Anjra y a una nueva prefectura, M'Diq-Finidq. Las dos nuevas unidades territoriales han sido receptoras de la mayor parte de las inversiones y actualmente la costa entre Ceuta y Martil es conocida como la "Marbella Marroquí".

Figura 5. División administrativa inicial de la Región Norte de Marruecos.

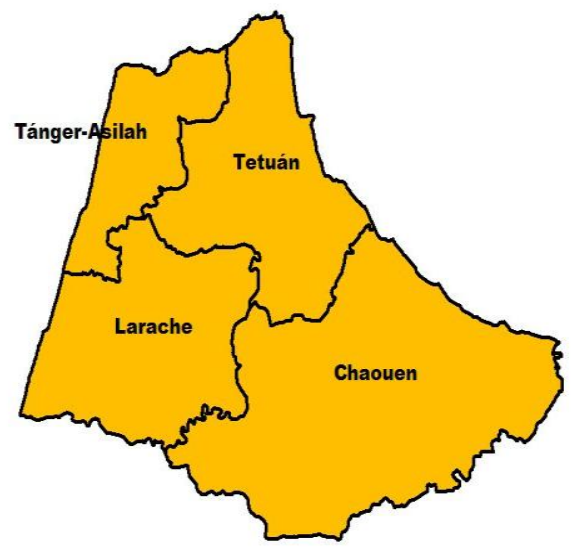

Fuente: Departamento de Geología de la Universidad Abdelmalek Essaadi.

Figura 6. División administrativa actual de la Región Tánger-Tetuán.

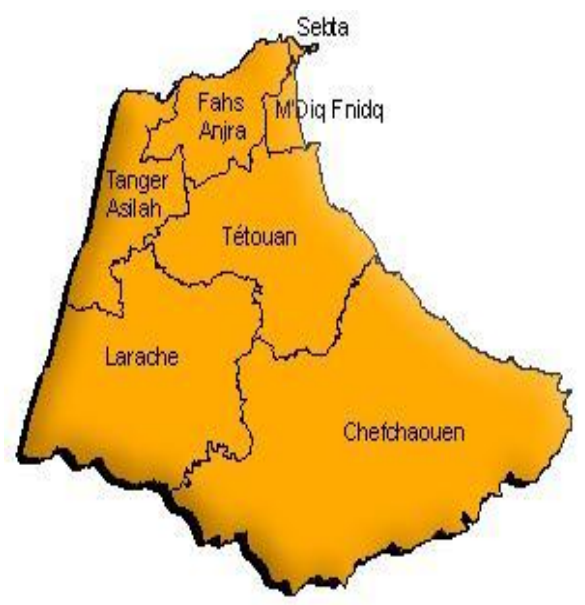

Fuente: Departamento de Geología de la Universidad Abdelmalek Essaadi.

ISSN: 0212-8594 ISSN-e: 2340-2776 № DOI: http://dx.doi.org/10.12795/rea.2011.i28.01 REA 28 (2011):1-15

http://www.publius.us.es/estudios_andaluces 


\subsection{EL COSTE DEL SDAU EN EL MEDIO NATURAL.}

Además del cambio del uso del suelo para la ubicación de las infraestructuras, la construcción de éstas ha acarreado un gran volumen de movimiento y extracción de materiales de construcción. Este hecho ha llegado hasta el punto de que en el ámbito rural ha cundido la extracción de gravas de cauces torrenciales como una actividad económica complementaria. Este hecho ha provocado la erosión de zonas agrícolas y otros negativos con la aparición de canteras sin control y degradación de cordones dunares (Khabali, 2012).

El estudio de estos impactos se ha realizado tras varias campañas de trabajo de campo con recogida de áreas de entrenamiento para la posterior clasificación de usos del suelo, siguiendo una serie temporal de más de una década. En la siguiente figura se recogen las tres zonas diferentes de estudio a) cauce bajo del Oued Laou (subcuenca) b) cuenca del Oued Laou y Reserva Transfronteriza del estrecho. Los puntos en amarillo señalan los puntos donde se han recogido muestras para la posterior clasificación. La clasificación de usos dio permitió averiguar el aumento de suelos cultivados en detrimento del suelo forestal, así como la aparición de nuevas zonas de extracción con aumento de arenas y gravas.

Figura 7. Zonas de trabajo de campo.

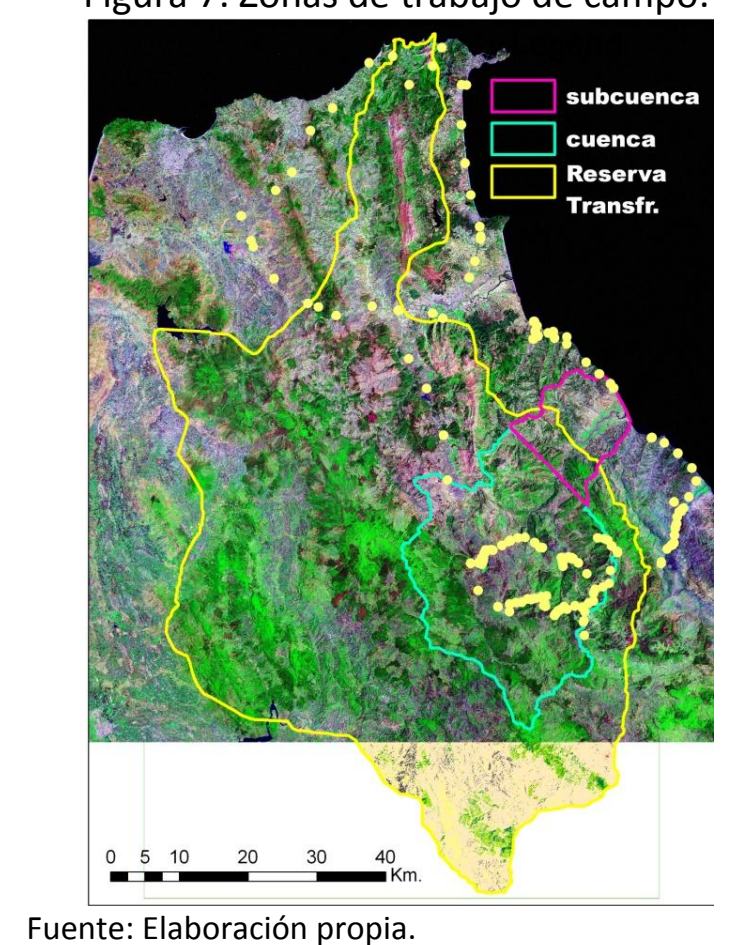

ISSN: 0212-8594 ISSN-e: 2340-2776 № DOI: http://dx.doi.org/10.12795/rea.2011.i28.01 REA 28 (2011):1-15

http://www.publius.us.es/estudios_andaluces 
Figura 8. Evolución de usos del suelo entre 2007 y 2009. Reserva Transfronteriza del Estrecho.

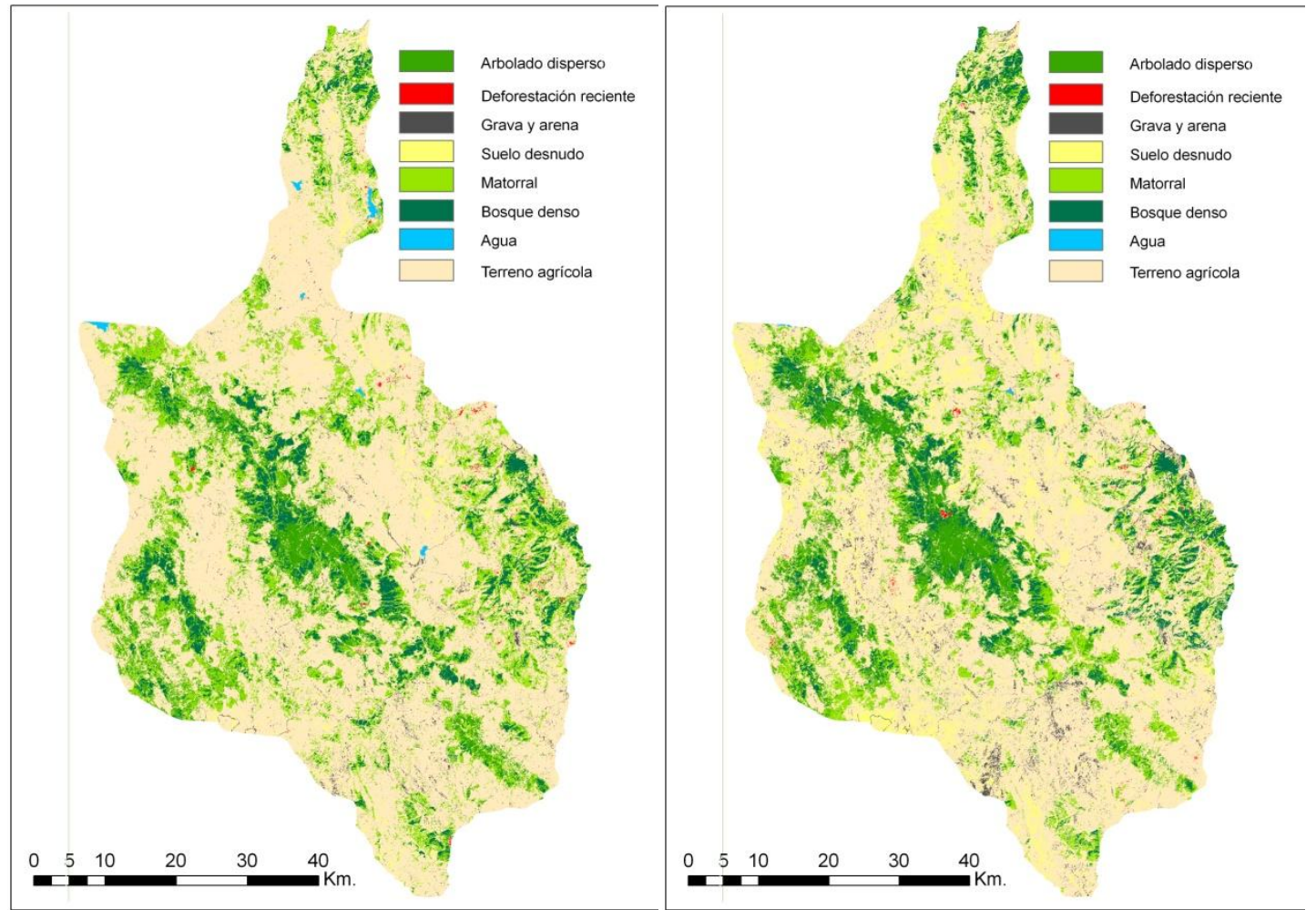

Fuente. Elaboración propia.

Además se ha podido averiguar la progresiva deforestación asociada a la necesidad de ganar territorio agrícola. En este último caso cabe destacar la deforestación de zonas arboladas de montaña advirtiéndose restos de incendios probablemente provocados. Por la localización de estas áreas y las condiciones del entorno, esta práctica la asociamos al tradicional cultivo de cannabis. Este cultivo es habitual en la zona, constituyendo en muchos casos un complemento económico para la población rural e incluso constituyendo un rasgo identificativo.

Figura 9. Zonas incendiadas y cultivadas posteriormente. 2007 y 2009.

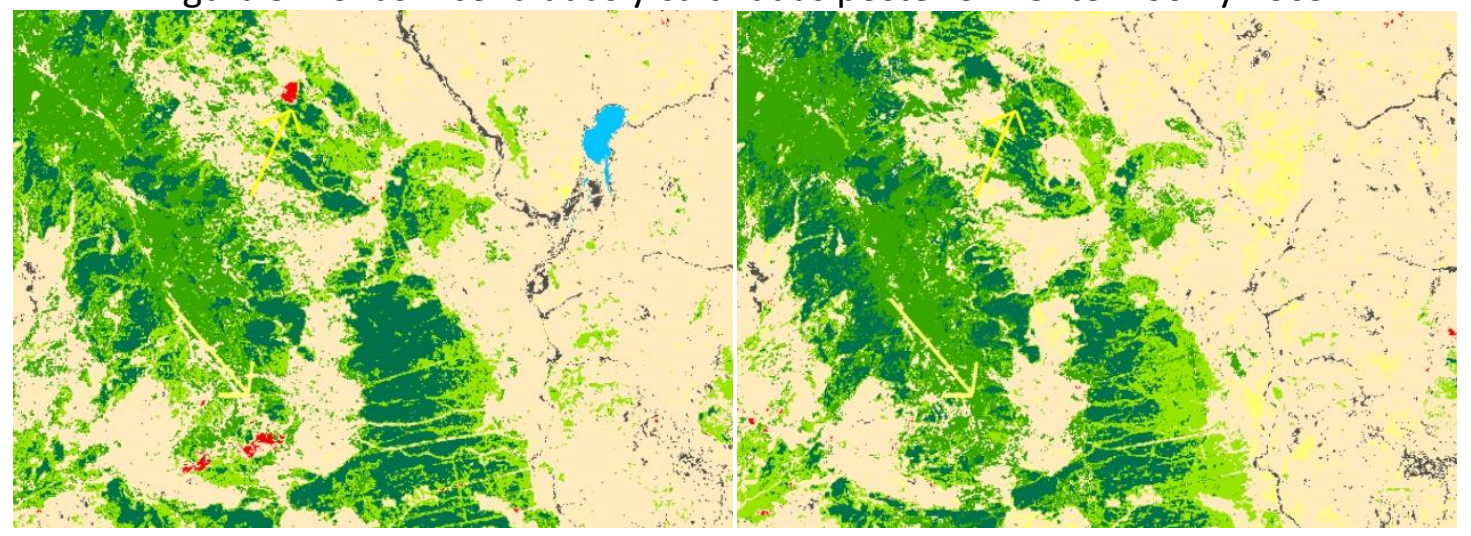

Fuente: Elaboración propia.

ISSN: 0212-8594 ISSN-e: 2340-2776 № DOI: http://dx.doi.org/10.12795/rea.2011.i28.01

REA 28 (2011):1-15

http://www.publius.us.es/estudios_andaluces 
Puede advertirse también la pérdida de masa forestal de porte arbustivo representada en verde más oscuro. El pantano de Chaouen se ha colmatado y ha quedado fuera de uso por el aporte de sedimentos.

\section{CONCLUSIONES.}

Las políticas desarrollistas suelen tener un coste medioambiental con mayor o menor trascendencia. El caso del Norte de Marruecos se nos presenta como un laboratorio excelente donde averiguar en una escala temporal asumible por el investigador las transformaciones que en otros casos han tardado varias décadas en suceder. La transformación radical promovida por el SDAU ha aumentado el atractivo en las zonas urbanas aumentando el éxodo rural que ya era de por sí considerable. La pérdida de calidad de vida la asociamos a la pérdida de suelo cultivable y el deterioro del medio al poner en cultivo tierras forestales. En la región norte de Marruecos no existe una agricultura industrial como sí ocurre en Larache y el entorno de Casablanca. La agricultura es de subsistencia y como tal está sometida a la supervivencia de las familias en un medio cada vez más desfavorable. La documentación cartográfica que se está elaborando por la Asociación deberá servir para justificar intervenciones en este medio que bien podrían tomar como ejemplo los patrones que se han aplicado en el entorno rural español, cuyo deterioro siguió pautas similares en un período de tiempo más largo.

\section{BIBLIOGRAFÍA.}

Chikhaoui (2000) Dimensión de la decentralisation au Maroc 13 pp. http://www1.kas.de/publikationen/2000/entwicklung/chikhaoui-fr.pdf 2 (marzo 2003)

Indice de Desarrollo Humano http://hdr.undp.org/es/ (Abril 2012)

Khabali (2012) L'Exploitation des carrières dans le littoral de Kenitra et sa zone d'influence : étude d'impact sur l'environnement. Tesis sin publicar.

Direction General de la Statístique http://www.hcp.ma/Direction-de-lastatistique_a716.html (Abril 2012)

Moreno NAVARRO J.G. (2008) Análisis con SIG del Transporte Intermodal Entre Marruecos y la Unión Europea. Bases para la Concepcion Estratégica del Estrecho de Gibraltar. Sevilla. Secretariado de Publicaciones de la Universidad de Sevilla. 454

Moreno, J.G.; Ventura, J. (2008): Perspectivas de las infraestructuras para el desarrollo territorial en el entorno del Estrecho de Gibraltar, en Revista de Estudios Andaluces, no 27, pp.65-86

Moreno Navarro, J.G.; Ventura Fernandez, J.; ALFARO SÁNCHEZ, A., (2007) El Estrecho de Gibraltar Como Encrucijada de Estrategias para el Desarrollo. La Geografía en la Frontera de los Conocimientos. Sevilla, España. Asociación Geógrafos Españoles. 2007. Pag. 1-12

ISSN: 0212-8594 ISSN-e: 2340-2776 № DOI: http://dx.doi.org/10.12795/rea.2011.i28.01

REA 28 (2011):1-15

http://www.publius.us.es/estudios_andaluces 
Moreno Navarro, J. G. (2006) Analisis con SIG de la Red de Transporte Intermodal Entre Marruecos y la Union Europea. Evaluacion de Rutas y Enclaves Estrategicos. Cuadernos Geograficos de la Universidad de Granada. 2006. Pag. 309-365

Moreno Navarro, J. G. (2006) Desarrollo Local en la Region Tanger-Tetuan. la Experiencia de un Proyecto Enfocado a la Creacion de Microempresas. III Congreso Universidad y Cooperacion al Desarrollo. III Congreso Universidad y Cooperacion al Desarrollo (3). Num. 3. Madrid. Ediciones de la Universidad Autónoma de Madrid. 2006. Pag. 143-157

USGS: glovis.usgs.go (abril 2012) 